\title{
Achievement goals and life satisfaction: the mediating role of perception of successful agency and the moderating role of emotion reappraisal
}

\author{
Wangshuai Wang ${ }^{1}$, Jie Li2 ${ }^{2}$, Gong Sun ${ }^{3}$, Zhiming Cheng ${ }^{4}$ and Xin-an Zhang ${ }^{1}$
}

\begin{abstract}
Achievement goals are cognitive representations that guide behavior to a competence-related future end state. Existing theories and empirical findings suggest that achievement goals are potentially related to life satisfaction. However, the relationship between achievement goals and life satisfaction remains relatively unexplored in the psychology literature. In this study, we examined how, why, and when achievement goals affect life satisfaction using original survey data from China. The results suggest that achievement goals were positively related to life satisfaction $\left(R^{2}=.20,90 \% \mathrm{Cl}[.11,26]\right)$, that the perception of successful agency fully mediated the relationship between achievement goals and life satisfaction $\left(R^{2}=.22,90 \% \mathrm{Cl}[.12, .27]\right)$, and that emotion reappraisal moderated the relationship between achievement goals and life satisfaction $\left(R^{2}=.34,90 \% \mathrm{Cl}[.23, .39]\right)$. Our study indicates that achievement goals have a positive influence on life satisfaction and help to elucidate the mechanism and boundary condition of this influence.
\end{abstract}

Keywords: Achievement goals, Perception of successful agency, Emotion reappraisal, Life satisfaction

\section{Background}

An achievement goal refers to "a future-focused cognitive representation that guides behavior to a competencerelated end state that the individual is committed to either approach or avoid" (Hulleman, Schrager, Bodmann, \& Harackiewicz, 2010, p. 423). In the past three decades, there has been a large body of literature published on achievement goals (see Hulleman et al., 2010, for a metaanalytic review). Existing research shows that individuals differ in their behaviors and preferences in pursuit of achievement goals (Harackiewicz \& Sansone, 1991). For example, one may easily recall that in school years, certain students worked hard and performed well on exams, demonstrating high achievement goals. In contrast, other students were not strongly concerned regarding academic performance, did not study, and had poor performance in exams, which denoted low motivation for achievement goals.

* Correspondence: mgmtli@i.shu.edu.cn

${ }^{2}$ Shanghai University, 99 Shangda Road, Shanghai, China

Full list of author information is available at the end of the article
One stream of research has identified the antecedents of achievement goals. For example, age is negatively related to achievement goals; females have a stronger mastery of goal orientation than males in an academic setting, whereas self-efficacy and perceived social environment, including peer relationships and sense of belonging, are positive predictors of achievement goals (Ablard \& Lipschultz, 1998; Anderman \& Anderman, 1999; Bong, 2009; Phillips \& Gully, 1997).

More recently, attention has been directed to the consequences of pursuing achievement goals. For instance, achievement goals positively predict long-term academic performance (Harackiewicz, Barron, Tauer, Carter, \& Elliot, 2000). Moreover, achievement goals can activate intrinsic motivation (Cury, Elliot, Sarrazin, Da Fonseca, \& Rufo, 2002). Based on this finding, Lee, Sheldon, and Turban (2003) argue that achievement goals promote academic enjoyment. In contrast, researchers also find that negative emotions can be exacerbated by achievement goals due to high expectations. For example, students aspiring for high 
achievement goals may experience more anxiety during tests (Flanagan, Putwain, \& Caltabiano, 2015).

The existing literature on life satisfaction shows that demographic variables, including gender, age, income, and education level, are associated with life satisfaction (Gannon \& Ranzijn, 2005; Johnson \& Krueger, 2006) and that a person who is more satisfied with life is more diligent, performs better at his/her job, and has a higher commitment to the organization (Efraty, Sirgy, \& Claiborne, 1991; Greenhaus, Bedeian, \& Mossholder, 1987). More recent research finds that expectation and aspiration are important to job and life satisfaction (Cheng, Wang, \& Smyth, 2014; Gao \& Smyth, 2010). Similarly, academic goal progress is found to influence both academic and life satisfaction (Ojeda, Flores, \& Navarro, 2011; Singley, Lent, \& Sheu, 2010). Furthermore, Keller and Siegrist (2010) suggest that both goal pursuit and life satisfaction are psychological resources.

Although these aforementioned studies suggest potential connections between achievement goals and life satisfaction, few studies have directly tested this relationship. In particular, it is unclear in the literature whether achievement goals influence life satisfaction in a positive or a negative way. On the one hand, individuals with high achievement goals can be substantially motivated by mental energy in the face of challenge (Grant \& Dweck, 2003). On the other hand, these people also need to make a concerted effort in the stressful and laborious process of pursuing their goals (Senko \& Harackiewicz, 2005).

People are paying increasing attention to the improvement of the quality of life. Life satisfaction's fundamental role and indispensability have been acknowledged by worldwide respondents (Diener, Oishi, \& Lucas, 2003). Therefore, to help fill the gaps in the literature and to respond to the practical necessity, this research examines the association between achievement goals and life satisfaction. We also investigate why and when achievement goals influence life satisfaction by examining the underlying mechanism through perception of successful agency and the boundary condition of emotion reappraisal. It is also surprising that little research on achievement goals, successful agency, and emotional reappraisal have been conducted in nonWestern cultures (e.g., Chinese culture), which leaves a potentially rewarding empirical research area to be explored. Existing studies suggest that there are significant cultural differences in positive psychology (e.g., Diener, Diener, \& Diener, 1995; Spencer-Rodgers, Peng, Wang, \& Hou, 2004). It is, therefore, very important to examine these constructs using data drawn from non-Western cultures.

Taken together, in this research, we first answer an important but unresolved question: what is the relationship between achievement goals and life satisfaction? We further advance our study by testing the potential mediation and moderation of this relationship. The current research also has significant practical implications for the general public-including but not limited to workers and students-on the means to successfully pursue greater happiness.

Life satisfaction is a global cognitive judgment across a broad set of activities concerning one's quality of life (Diener et al., 2003; Matud, Bethencourt, \& Ibáñez, 2014). Various factors are related to life satisfaction, such as finances (Johnson \& Krueger, 2006), family and marital relationships (Adams, King, \& King, 1996; Cheng \& Smyth, in press), health conditions (Canha, Simões, Matos, \& Owens, 2016), coping strategies (Nunes, Melo, Júnior, \& Eulálio, 2016), and sexual behaviors (Cheng \& Smyth, 2015).

Although the direct evidence for the link between achievement goals and life satisfaction is limited, previous research has provided some indirect support. For instance, the self-determination theory theorizes two forms of motivation, which are controlled motivation and autonomous motivation (Ryan \& Deci, 2000). Controlled motivation originates either from self-imposed pressures or from external pressures, such as pleasing others or complying with demands, both of which have an externally perceived locus of causality. In contrast, autonomous motivation stems from one's self, thereby having an internally perceived locus of causality (Weinstein \& Ryan, 2010). Setting high achievement goals, in many cases, reflects one's own values; thus, it is internally driven and inspires autonomous motivation (Cury et al., 2002). Importantly, literature based on self-determination theory indicates that autonomous motivation positively contributes to well-being (Ryan \& Deci, 2000).

Moreover, individuals often want to maintain a sense of control, expecting everything to be in line with their plans (Park \& Baumeister, 2017). However, there are always discrepancies between expectations and reality. Under certain circumstances, the experiences of hardships often demotivate people and make them feel dissatisfied with life. Achievement goals can provide a person with motivation (Pintrich, 2000), which serves as mental energy helpful in overcoming the difficulties and obstacles in life (Capa, Audiffren, \& Ragot, 2008). As a result, people who set achievement goals for themselves are less affected by experiences that can have negative effects on life satisfaction.

Furthermore, researchers find that setting achievement goals is helpful to one's educational and occupational performance, since it results in better grades at school and upward career mobility (Gould, 1980; Harackiewicz et al., 2000; Harackiewicz, Barron, Tauer, \& Elliot, 2002). The successes in academic and job domains boost selfefficacy and self-esteem (Bachman \& O'Malley, 1977; Leary, Tambor, Terdal, \& Downs, 1995; Tay, Ang, \& Van Dyne, 2006), both of which can enhance satisfaction with life (Du, Bernardo, \& Yeung, 2015; Joseph, Royse, 
Benitez, \& Pekmezi, 2014). Therefore, we propose the following hypothesis:

\section{Hypothesis 1: Achievement goals are positively correlated with life satisfaction.}

Perception of successful agency is a sense of determination to be successful in pursuing goals, by which hope is fueled (Snyder et al., 1991). Perception of successful agency is conceptually similar to self-efficacy, and they are shown to be positively and moderately correlated (Magaletta \& Oliver, 1999). However, successful agency is more future-oriented than is self-efficacy (Snyder et al., 1991). Thus, perception of successful agency is more closely related to achievement goals compared to self-efficacy.

We hypothesize that achievement goals are positively related to perception of successful agency. This is because achievement goals usually lead people to maintain high standards and strive to accomplish difficult tasks (Phillips \& Gully, 1997). After making every effort to ensure success, people are likely to hold positive expectations towards the outcomes. This notion is supported by the effort justification theory (Aronson \& Mills, 1959), which states that people's expectations are in direct proportion to his/her effort. As expectations continue rising, they tend to attribute an even greater value to an outcome that they put effort into achieving.

In addition, we propose that perception of successful agency is positively associated with life satisfaction for two reasons. First, perception of successful agency makes one's life meaningful. Feldman and Snyder (2005) suggest that perception of successful agency per se is actually a component of meaning, because factor analysis shows a single factor underlying the two constructs. People who feel that their life is more meaningful also report higher satisfaction with life (Park, Park, \& Peterson, 2010; Steger, Frazier, Oishi, \& Kaler, 2006). Second, according to the notion that hope copes with obstacles and enhances meaning in life, several empirical research has revealed a positive relationship between hope and life satisfaction (Bailey, Eng, Frisch, \& Snyder, 2007; Bronk, Hill, Lapsley, Talib, \& Finch, 2009; O'Sullivan, 2011; Przepiorka, 2017). Because perception of successful agency is one dimension of hope, we expect its relationship with life satisfaction to be similar. Based on the above discussion, we hypothesize that:

Hypothesis 2: Perception of successful agency mediates the relationship between achievement goals and life satisfaction.

Individuals exert considerable control over their emotions but differ in their use of specific emotion regulation strategies. Of these, the two most widely used strategies are reappraisal and suppression (Gross \& John, 2003). Emotion reappraisal is a cognitive change of emotional impact by construing a potentially emotion-eliciting situation. For example, people can feel upset or frustrated in a traffic jam. However, if drivers reevaluate the current situation and consider a traffic jam as an unexpected opportunity to enjoy the beautiful scenery along the road, they can probably feel better off. This act of recognizing and changing the pattern of thoughts falls into emotion reappraisal. Compared with suppression, reappraisal is a much more effective regulation strategy (Gross, 1998; Gross \& John, 2003). People who habitually use emotion reappraisal are less likely to be depressed (Feinberg, Willer, Antonenko, \& John, 2012), experience more positive emotions and fewer negative emotions, and have better social functioning (Gross \& John, 2003).

Achievement goals promote one's expectation of the end state, which cannot always remain perfect. Failing to meet a goal means that most of the early efforts become sunk costs, which leads to decreased self-confidence and increased selfblame. These negative self-cognitions, in turn, trigger severe emotional reactions (Brown \& Dutton, 1995), such as depression and anxiety (Ellenhorn, 2005; Hewitt \& Flett, 1991). Consequently, when emotion reappraisal is low, the negative consequences caused by failure are unable to be adjusted in time, which lowers a person's perceived quality of life. In this condition, the positive relationship between achievement goals and life satisfaction is attenuated. In contrast, when emotion reappraisal is high, individuals take an optimistic attitude to negotiate stressful situations and thus become more immune to the pressure of goal failure (Gross \& John, 2003). As a result, their satisfaction with life remains positively correlated with achievement goals. Therefore, we propose the following hypothesis:

\section{Hypothesis 3: Emotion reappraisal moderates the positive relationship between achievement goals and life satisfaction, such that the relationship is stronger when emotion reappraisal is high rather than low.}

\section{Methods}

\section{Participants and procedures}

Data were collected via a survey from a sample of 225 participants in mainland China in late 2016 using Sojump (http://www.sojump.com), which is a professional online survey platform similar to Amazon's Mechanical Turk. Sojump has a large, diverse workforce consisting of over 2.6 million users with different demographic backgrounds. It provides reliable crowdsourcing services and has been used in previous psychological research (e.g., Chen, Austin, Miller, \& Piercy, 2015; Li, Chen, \& Huang, 2015). Respondents in the current study were randomly recruited from Sojump. Before starting the survey, they were told that their 
responses would remain confidential. After completing the survey, they received a monetary reward. Previous research has documented that giving a monetary reward to participants can improve their motivation in responding, thus being beneficial to the quality of survey data (Esterman, Reagan, Liu, Turner, \& DeGutis, 2014). Online studies even amplify this advantage. A monetary incentive can inspire participants to respond carefully when researchers are unable to monitor how the participants fill in the survey, which is why plenty of psychological studies using online platforms pay for participation (e.g., Saleem, Anderson, \& Barlett, 2015; Stroessner, Scholer, Marx, \& Weisz, 2015).

All of the respondents were adults. Among the respondents, 106 were males, and 119 were females; 73, 23, and $4 \%$ of them were $18-35,36-53$, and above 54 years old, respectively. Forty-one and $42 \%$ of the respondents' monthly salary ranged from 2000 to 4000 yuan and from 4001 to 6000 yuan, respectively. The majority of the sample was well-educated: 53,21 , and $6 \%$ of them held bachelor's degrees, master's degrees, and $\mathrm{PhDs}$ as their highest degrees, respectively. With regard to job tenure, $63 \%$ of the participants had worked in their companies for more than 4 years, whereas 29 and $8 \%$ of them had worked in their companies for 2 to 3 years and less than 2 years, respectively.

\section{Measures}

We created a Chinese version of a set of measures for achievement goals, emotion reappraisal, perception of successful agency, life satisfaction, and social desirability. To ensure the accuracy of the translation, we followed Brislin's (1986) translation and back-translation procedures. Specifically, the items of the scales were first translated into Chinese by a native Chinese speaker with excellent knowledge of English. Next, this process was reversed by a native English speaker with excellent command of Chinese. For a very small number of items, the back-translation procedure resulted in inconsistencies. However, these inconsistencies were resolved by discussion between the two translators and the researchers. To further validate the translation, we conducted a pretest involving 20 randomly recruited participants from Sojump before implementing the formal survey. After the completion of the pretest survey, participants declared that the survey questions were easily understood and that there were no barriers to responding. The participants in the pilot study were not included in the final sample because combining two sources of samples may rule in the confounding due to different times of data collection. Moreover, we performed another set of statistical analyses with the participants in both the pilot and formal study. No significant difference was found compared with the current results. Therefore, we only reported the analyses in the formal study.

\section{Achievement goals}

Achievement goals were measured by the Achievement Goal Striving Scale, which is a ten-item scale adapted from Goldberg's (1999) International Personality Item Pool (IPIP). It has been widely used in previous studies and has proven to have good reliability and validity (Hirschfeld, Lawson, \& Mossholder, 2004). On a seven-point scale $(1=$ not at all characteristic $;=$ very characteristic $)$, participants rated how characteristic each statement best described themselves. An example item is "I go straight for the goal." We used Omega to estimate reliability, because compared to Cronbach's alpha, Omega provides a better estimate with more appropriate assumptions (Crutzen \& Peters, 2017; McNeish, in press). All of the items were averaged to create the score for achievement goals (Omega $=.91)$.

\section{Emotion reappraisal}

Emotion reappraisal was assessed using the reappraisal subscale of the Emotion Regulation Questionnaire. This instrument is a six-item measure developed by Gross and John (2003). Participants indicated their agreement with each item on a seven-point scale ( 1 = strongly disagree; 7 = strongly agree). An example item is "I control my emotions by changing the way I think about the situation I'm in." All of the items were averaged to create the score for emotion reappraisal (Omega $=.96)$.

\section{Perception of successful agency}

We measured perception of successful agency using Snyder et al.'s (1991) Agency subscale of the Hope Scale (e.g., Chang, 2003; Gallagher \& Lopez, 2009), which consists of four items. Participants were asked to evaluate the extent to which each item applied to them on a sevenpoint scale $(1=$ definitely false; $7=$ definitely true $)$. An example item is "I energetically pursue my goals." All of the items were averaged to create the score for perception of successful agency (Omega $=.95)$.

\section{Life satisfaction}

We assessed life satisfaction using the five-item Satisfaction with Life Scale developed by Diener, Emmons, Larsen, and Griffin (1985). On a seven-point scale $(1=$ strongly disagree; 7 = strongly agree), participants reported the overall satisfaction with their life under different indicators. An example item is "In most ways my life is close to my ideal." All of the items were averaged to create the score for life satisfaction (Omega $=.94)$.

\section{Control variables}

In the survey, we also collected information on some important variables that are potentially correlated with life satisfaction, such as gender, age, income, education level (Gannon \& Ranzijn, 2005; Johnson \& Krueger, 2006), 
job tenure (Adams et al., 1996), and social desirability bias. We used the Marlowe-Crowne Social Desirability Scale (Form C) with 13 true-false format items (Reynolds, 1982) to assess social desirability (Omega $=.77$ ). An example item is "It is sometimes hard for me to go on with my work."

\section{Data analysis}

We began the analyses by conducting a series of confirmatory factor analyses using LISREL8.8, to verify the distinctness of the variables included in our models. Because our sample size was relatively small, we constructed item parcels in these confirmatory factor analyses. Specifically, four indicators were formed for constructs that contained more than four items by sequentially grouping the highest loading items with the lowest loading ones (Little, Cunningham, Shahar, \& Widaman, 2002). After parceling, the total number of indicators decreased to 16 , since the number of parcels for each construct was four. We assessed the models by comparing four indicators of fit, including the chi-square/degrees of freedom ratio $\left(\chi^{2} / d f\right)$, comparative fit index (CFI), non-normed fit index (NNFI), and root mean square error of approximation (RMSEA). Good fits are obtained when $\chi^{2} / d f$ is less than 5 and RMSEA is less than .10, whereas NNFI and CFI are greater than or equal to .90 (Bentler, 1990; Steiger, 1990).

Prior to hypothesis testing, we conducted exploratory factor analyses to ensure that the scales used retained their intended structure (Crutzen \& Peters, 2017). Next, correlations among study variables were calculated using Pearson's correlation coefficients, providing initial support for the hypotheses. Next, we performed hierarchical regressions using SPSS for the purpose of hypothesis testing, in which independent variables were mean-centered to reduce multicollinearity (Cohen, Cohen, West, \& Aiken, 2003). Afterwards, as a robustness check for small samples (Preacher \& Hayes, 2008), we used a bias-corrected and accelerated bootstrapping procedure (5000 samples were taken) to further examine the achievement goal-perception of successful agency-life satisfaction link. Next, simple slope analysis was applied to probe the nature of the interaction effect (Aiken \& West, 1991). Finally, we employed another statistical analysis, which included both successful agency and emotion reappraisal in a single model. Again, we adopted the bootstrapping method as in Model 5 in Hayes (2013). As suggested by Cohen (1990), we reported all effect sizes and confidence intervals in the statistical analyses. Fisher's $z$ and its 95\% confidence intervals were calculated in the correlational analysis (Rosenthal, 1991). We chose $R^{2}$ as the index of effect sizes for regression analyses and computed the $90 \%$ confidence interval for each $R^{2}$ (Smithson, 2001).

To support disclosure and replication in scientific research (Peters, Abraham, \& Crutzen, 2015) and facilitate future meta-analyses, the data, syntax and statistical outputs used in the present study are available at https://pan. baidu.com/s/1qXLFvq8.

\section{Results}

\section{Exploratory factor analyses}

The measurement instruments were in line with their intended structure, as a single latent variable was observed for each construct, and all scales used in this research were unidimensional (Crutzen \& Peters, 2017).

\section{Measurement model results}

The baseline model contained four factors: achievement goals, emotion reappraisal, perception of successful agency, and life satisfaction. We also examined six alternative models against the baseline model. As shown in Table 1, the results suggested that the baseline model fits the data reasonably well $\left(\chi^{2}(98)=348.79, \mathrm{CFI}=.96\right.$, NNFI $=.95$, RMSEA $=.09$ ). The alternative models all exhibited significantly poorer fit than the baseline model. Therefore, we treated the four variables as distinct constructs in later analyses.

\section{Descriptive statistics and correlations}

All scales met the distributional assumptions with skewness and kurtosis values lower than \pm 1 . More specifically, the absolute values for skewness (kurtosis) ranged from .02 to .59 (.19 to .69 ). The descriptive statistics and correlations among variables are presented in Table 2. Age was positively related to gender $(r=.16, p<.05$; Fisher's $z=.16,95 \%$ CI $[.03, .29])$ and income $(r=.30, p<.01$; Fisher's $z=.31,95 \%$ CI [.18, .44]); education was positively correlated with income $(r=.24, p<.01$; Fisher's $z=.24$, $95 \%$ CI $[.11, .37])$ and negatively correlated with job tenure $(r=-.26, p<.01$; Fisher's $z=-.27,95 \%$ CI $[-.14,-.40])$. Consistent with our hypotheses, achievement goals had a significant positive correlation with life satisfaction $(r=.42, p<.01$; Fisher's $z=.45,95 \%$ CI $[.32, .58])$ and perception of successful agency $(r=.83, p<.01$; Fisher's $z=1.12$, 95\% CI $[.99,1.25])$. Perception of successful agency was also significantly related to life satisfaction $(r=.44, p<.01$; Fisher's $z=.47,95 \%$ CI $[.34, .60])$.

\section{Hypotheses test results}

Table 3 displays the results of the regression analyses for testing Hypothesis 1 (achievement goals are positively related to life satisfaction) and Hypothesis 2 (perception of successful agency mediates the relationship between achievement goals and life satisfaction). The results supported these hypotheses. First, achievement goals were positively and significantly related to life satisfaction $\left(\beta=.42, p<.01 ; R^{2}=.20,90 \% \mathrm{CI}[.11, .26]\right)$, supporting 
Table 1 Comparison of results from the measurement models

\begin{tabular}{|c|c|c|c|c|c|c|c|}
\hline Model & Description & $x^{2}$ & $d f$ & $\Delta x^{2}$ & $\mathrm{CFI}$ & NNFI & RMSEA \\
\hline Null model & All the indicators are independent & 7781.41 & 114 & & .01 & -.05 & .54 \\
\hline Baseline model & Four factors & 348.79 & 98 & & .96 & .95 & .09 \\
\hline Model 1 & $\begin{array}{l}\text { Three factors: achievement goals and perception of successful agency were } \\
\text { combined into one factor }\end{array}$ & 1078.99 & 101 & $730.20^{* *}$ & .87 & .84 & .20 \\
\hline Model 2 & Three factors: achievement goals and life satisfaction were combined into one factor & 1360.17 & 101 & $1011.38^{* *}$ & .83 & .80 & .23 \\
\hline Model 3 & $\begin{array}{l}\text { Three factors: achievement goals and emotion reappraisal were combined into } \\
\text { one factor }\end{array}$ & 1453.42 & 101 & $1104.63^{* *}$ & .82 & .79 & .24 \\
\hline Model 4 & $\begin{array}{l}\text { Three factors: perception of successful agency and life satisfaction were combined } \\
\text { into one factor }\end{array}$ & 1131.96 & 101 & $783.17^{* *}$ & .86 & .84 & .21 \\
\hline Model 5 & $\begin{array}{l}\text { Three factors: perception of successful agency and emotion reappraisal were } \\
\text { combined into one factor }\end{array}$ & 1434.94 & 101 & $1086.15^{* *}$ & .82 & .79 & .24 \\
\hline Model 6 & Three factors: emotion reappraisal and life satisfaction were combined into one factor & 1409.60 & 101 & $1060.81^{* *}$ & .82 & .79 & .24 \\
\hline
\end{tabular}

$N=225 ; \Delta x^{2}$ is the change of $x^{2}$ compared with the baseline model

${ }^{* *} p<.01$

Hypothesis 1. Second, to test mediation, we followed Baron and Kenny's procedure (1986).

In Model 1, we regressed successful agency on the control variables and achievement goals. In Model 2, we regressed life satisfaction on the same variables as in Model 1. In Model 3, we regressed life satisfaction on the controls, achievement goals, and successful agency. The results supported Hypothesis 2. First, achievement goals were significantly related to successful agency $\left(\beta=.85, p<.01 ; R^{2}=.71,90 \%\right.$ CI $\left.[.65, .74]\right)$. Second, achievement goals were significantly related to life satisfaction $\left(\beta=.42, p<.01 ; R^{2}=.20,90 \%\right.$ CI $\left.[.11, .26]\right)$. Third, successful agency was significantly related to life satisfaction $\left(\beta=.25, p<.01 ; R^{2}=.22,90 \%\right.$ CI $\left.[.12, .27]\right)$, even after achievement goals were controlled for. In addition, the insignificant coefficient for achievement goals $(\beta=.20$, $p>.05)$ indicated that successful agency completely mediated the relationship between achievement goals and life satisfaction. Furthermore, a 5000 resample bootstrap suggested a significant indirect effect via successful agency $(b=.24, \mathrm{SE}=.09,95 \% \mathrm{CI}[.06, .42])$. This finding again supported Hypothesis 2. Additionally, following MacKinnon, Lockwood, Hoffman, West, and Sheets (2002), we calculated the $z$ coefficient, which results from the division of the mediated effect by its standard error. Consistent with prior findings, the calculation yielded a significant result $(z$ value $=2.24, p<.05)$.

Table 4 presents the results for the tests of Hypothesis 3. Model 1 contained the control variables only. In Model 2, achievement goals and emotion reappraisal were added. In Model 3, the interaction term between achievement goals and emotion reappraisal was added. In support of Hypothesis 3, the interaction effect of achievement goals and emotion reappraisal was statistically significant

Table 2 Descriptive statistics, coefficient alphas, and zero-order correlations between variables

\begin{tabular}{|c|c|c|c|c|c|c|c|c|c|c|c|c|}
\hline & M & SD & 1 & 2 & 3 & 4 & 5 & 6 & 7 & 8 & 9 & 10 \\
\hline 1. Achievement goals & 5.08 & 1.42 & $(.90)$ & & & & & & & & & \\
\hline 2. Emotion reappraisal & 4.27 & 1.67 & $.35^{* *}$ & $(.95)$ & & & & & & & & \\
\hline 3. Perception of successful agency & 5.38 & 1.38 & $.83^{* *}$ & $.27^{* *}$ & $(.95)$ & & & & & & & \\
\hline 4. Life satisfaction & 4.55 & 1.42 & $.42^{* *}$ & $.36^{* *}$ & $.44^{* *}$ & $(.93)$ & & & & & & \\
\hline 5. Gender & & & $-.17^{*}$ & -.04 & -.07 & -.02 & & & & & & \\
\hline 6. Age & 2.25 & .50 & .03 & -.10 & .01 & .01 & $.16^{*}$ & & & & & \\
\hline 7. Income & 2.76 & 1.14 & .12 & -.05 & $.15^{*}$ & .10 & -.12 & $.30^{* *}$ & & & & \\
\hline 8. Education & 3.44 & .76 & -.05 & -.06 & .01 & -.05 & -.05 & .12 & $.24^{* *}$ & & & \\
\hline 9. Job tenure & 2.70 & .97 & -.05 & -.02 & .01 & .10 & .02 & .06 & -.02 & $-.26^{* *}$ & & \\
\hline 10. Social desirability & 1.52 & .31 & .12 & $.43^{* *}$ & .09 & .12 & .02 & -.05 & -.07 & $-.18^{* *}$ & .05 & $(.77)$ \\
\hline
\end{tabular}

$N=225$; age: $1=$ less than 18 years old, $2=18-35$ years old, $3=36-53$ years old $4=$ more than 54 years old; (monthly) income: $1=$ less than 2000 yuan; $2=2000-4000$ yuan; $3=4001-6000$ yuan; $4=$ more than 6000 yuan; education: $1=$ high school, $2=$ some college, $3=$ bachelor's degree, $4=$ master's degree, $5=$ doctoral degree; job tenure: $1=$ less than 2 years, $2=2-3$ years, $3=4-5$ years, $4=$ more than 6 years; social desirability: $1=$ true, $2=$ false

${ }^{*} p<.05$

${ }^{* *} p<.01$ 
Table 3 Results for main effect and mediation from hierarchical regression

\begin{tabular}{llll}
\hline & $\begin{array}{l}\text { Model 1: Perception } \\
\text { of successful agency }\end{array}$ & $\begin{array}{l}\text { Model 2: Life } \\
\text { satisfaction }\end{array}$ & $\begin{array}{l}\text { Model 3: Life } \\
\text { satisfaction }\end{array}$ \\
\hline Controls & & .06 & .04 \\
Gender & .08 & -.04 & -.03 \\
Age & .05 & .07 & .06 \\
Income & .07 & .01 & -.01 \\
Education & .06 & .12 & .10 \\
Job tenure & -.05 & .07 & .07 \\
Social desirability & .01 & & \\
Main effects & & $.42^{* *}$ & .20 \\
Achievement & $.85^{* *}$ & & $.25^{*}$ \\
goals & & & $7.71^{* *}$ \\
Perception of & & $7.94^{* *}$ & .22 \\
successful agency & & .20 & .19 \\
$F$ & $77.19^{* *}$ & .18 & $.02^{* *}$ \\
$R^{2}$ & .71 & & {$[.12, .27]$} \\
Adjusted $R^{2}$ & .70 & &
\end{tabular}

Cls are confidence intervals for effect sizes; $N=225$

$p<.05$

${ }^{* * *} p<.01$

$\left(\beta=.31, p<.01 ; R^{2}=.34,90 \%\right.$ CI $\left.[.23, .39]\right)$, and there was a significant change in the multiple squared correlation coefficient $\left(\Delta R^{2}\right)$.

Figure 1 shows that the effect of the two-way interaction between achievement goals and emotion reappraisal was in the expected direction. Following the simple slope analyses, we found that achievement goals at a high level of emotion reappraisal were positively related to life satisfaction $(\beta=1.29, p<.01)$, whereas achievement goals at a low level of emotion reappraisal were not significantly related to life satisfaction $(\beta=.10, p>.30)$.

Finally, a model that included both successful agency and emotion reappraisal was tested. Figure 2 illustrates the coefficients $\left(R^{2}=.34,90 \%\right.$ CI $\left.[.24, .40]\right)$. The interaction term remained significant and the indirect effect of achievement goals on life satisfaction through successful agency was also significant $(b=.27, \mathrm{SE}=.09,95 \%$ CI $[.10, .44])$. These results provided convergent support for our hypotheses.

\section{Discussion}

This study used original survey data to examine the influence of achievement goals on life satisfaction, the mediating role of perception of successful agency, and the moderating role of emotion reappraisal. Consistent with our predictions, achievement goals are positively associated with life satisfaction. Furthermore, we show that this relationship is mediated by perception of successful
Table 4 Results for moderation from hierarchical regression

\begin{tabular}{|c|c|c|c|}
\hline & \multicolumn{3}{|c|}{ Life satisfaction } \\
\hline & Model 1 & Model 2 & Model 3 \\
\hline \multicolumn{4}{|l|}{ Controls } \\
\hline Gender & .00 & .06 & .07 \\
\hline Age & -.02 & -.02 & -.01 \\
\hline Income & .13 & .08 & .09 \\
\hline Education & -.03 & -.01 & .01 \\
\hline Job tenure & .09 & .12 & $.16^{*}$ \\
\hline Social desirability & .12 & -.02 & -.04 \\
\hline \multicolumn{4}{|l|}{ Main effects } \\
\hline Achievement goals & & $.34^{* *}$ & $.35^{* *}$ \\
\hline \multicolumn{4}{|l|}{ Moderators } \\
\hline Emotion reappraisal & & $.26^{* *}$ & $.23^{* *}$ \\
\hline \multicolumn{4}{|l|}{ Interactions } \\
\hline $\begin{array}{l}\text { Achievement goals } \times \text { emotion } \\
\text { reappraisal }\end{array}$ & & & $.31^{* *}$ \\
\hline$F$ & 1.56 & $9.07^{* *}$ & $12.38^{* *}$ \\
\hline$R^{2}$ & .04 & .25 & .34 \\
\hline$\Delta R^{2}$ & & $.21^{* *}$ & $.09^{* *}$ \\
\hline $90 \% \mathrm{Cl}$ & {$[.00, .07]$} & {$[.14, .29]$} & {$[.23, .39]$} \\
\hline
\end{tabular}

agency. The simple slope analyses reveal that the positive relationship between achievement goals and life satisfaction holds when emotion reappraisal is high but not when it is low.

The present research contributes to the literature in three ways. First, we contribute to the scant literature on the relationship between achievement goals and life satisfaction. Our findings help fill this gap by showing that achievement goals are positively correlated with life satisfaction. The previous literature provides indirect and mixed evidence for this relationship (Lee et al., 2003; Senko \& Harackiewicz, 2005). We reconcile these differences by empirically testing this relationship, thereby adding to the literature investigating the consequences of achievement goals (e.g., Harackiewicz et al., 2000; Cury et al., 2002; Lee et al., 2003; Flanagan et al., 2015). This finding is also in alignment with previous research documenting the overlap between aspiration and well-being (e.g., Cheng et al., 2014; Gao \& Smyth, 2010). However, aspiration involves positive expectations regardless of how much effort has been exerted, which obviously should positively contribute to happiness. In contrast, the present research shows that even if considerable effort must be devoted, setting achievement goals is still beneficial to well-being. Therefore, this study complements previous findings by going beyond the aspiration effect. 


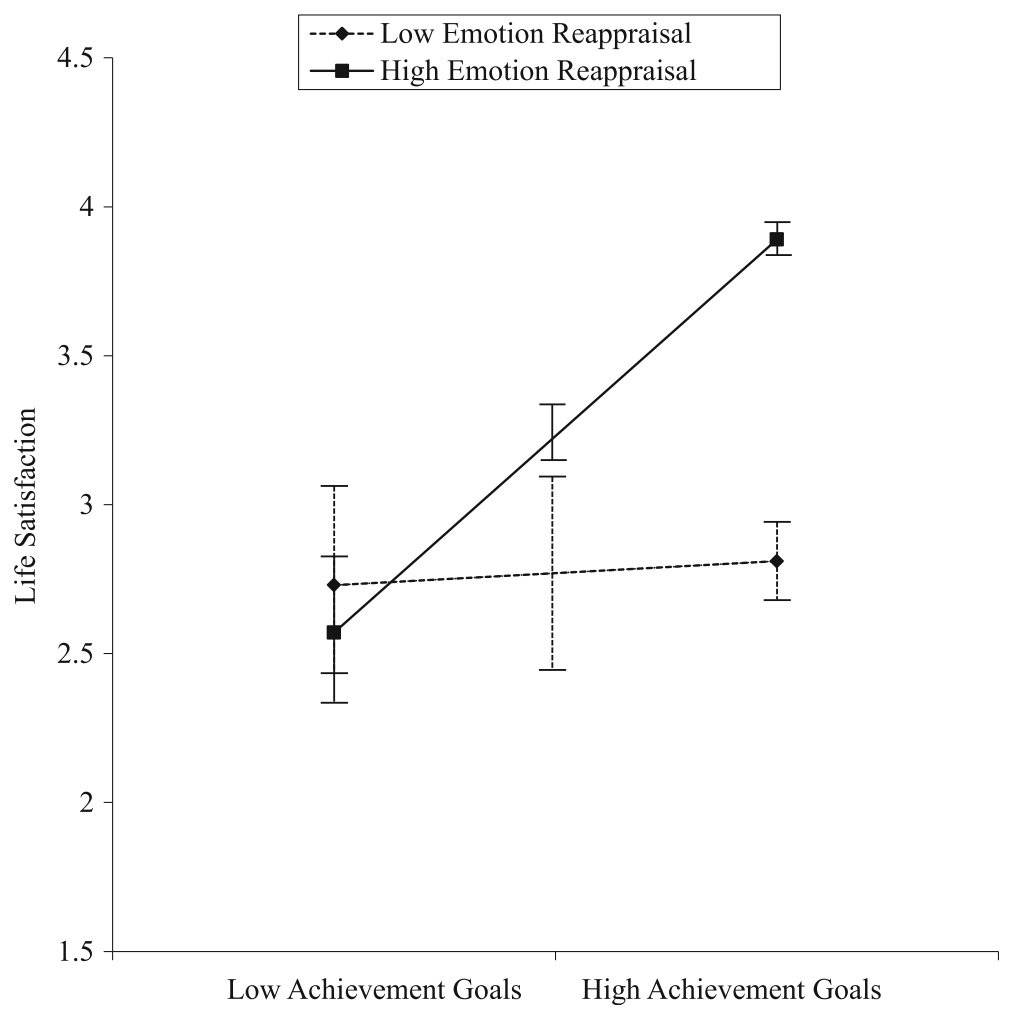

Fig. 1 Simple slope analyses. Moderating effect of emotion reappraisal on the relationship between achievement goals and life satisfaction. Error bars represent standard errors

Second, we identify the psychological process through which achievement goals are related to life satisfaction. Therefore, we shed some light on the role of perception of successful agency in the relationship between achievement goals and life satisfaction. This finding is consistent with the extant literature showing hope as a positive predictor of life satisfaction (Bailey et al., 2007; Bronk et al., 2009; O'Sullivan, 2011). Our research further demonstrates that perception of successful agency, as a dimension of hope, also contributes to life satisfaction. Given that hope is a multidimensional construct and that little research has probed into its sub-dimensions' downstream effects, the present research serves as a pioneer study.

Third, we examine the moderating role of emotion reappraisal to provide a richer understanding of the relationship between achievement goals and life satisfaction. We show that by cognitively reappraising emotion, people who set achievement goals live a happier life. This result is in line with a body of research that elucidates the positive function of emotion reappraisal in buffering anxiety and enhancing well-being (Feinberg et al., 2012; Gross \& John, 2003). Moreover, self-determination theory suggests a positive link between autonomous motivation and wellbeing (Ryan \& Deci, 2000). Through examining the moderating role of emotion reappraisal, we specify the boundary condition under which the positive relationship between achievement goals, a form of autonomous motivation, and well-being ceases to exist. Thus, our study represents an important advancement in self-determination theory.

The findings also offer valuable insights into practice. For example, enhancing employee's job satisfaction is of vital importance for many organizations. This research implies that organizations can boost employee's job satisfaction by inspiring their motivation for achievement goals. In addition, we find that if individuals suffer from failure in the process of goal pursuit, they need to reappraise their emotions to restore well-being. Emotion reappraisal can function as a catalyst for well-being when the situation goes against one's wishes (Gross \& John, 2003). The reason why it helps individuals to be less affected by negative events is that emotion reappraisal ccurs early in the emotion-generative process and alters the trajectory of the emotion before the emotional response is generated (Gross, 2002). This has direct practical implications for career development. Consider a scenario in which an ambitious young man aims high in career development and spares no effort at work to get a promotion. However, it turns out that one of his competing colleagues receives the promotion instead, so he fails to achieve his promotion goal at present. Under this circumstance, if he leverages the emotion reappraisal strategy, he may see the competitive situation as an external force that drives him to become 


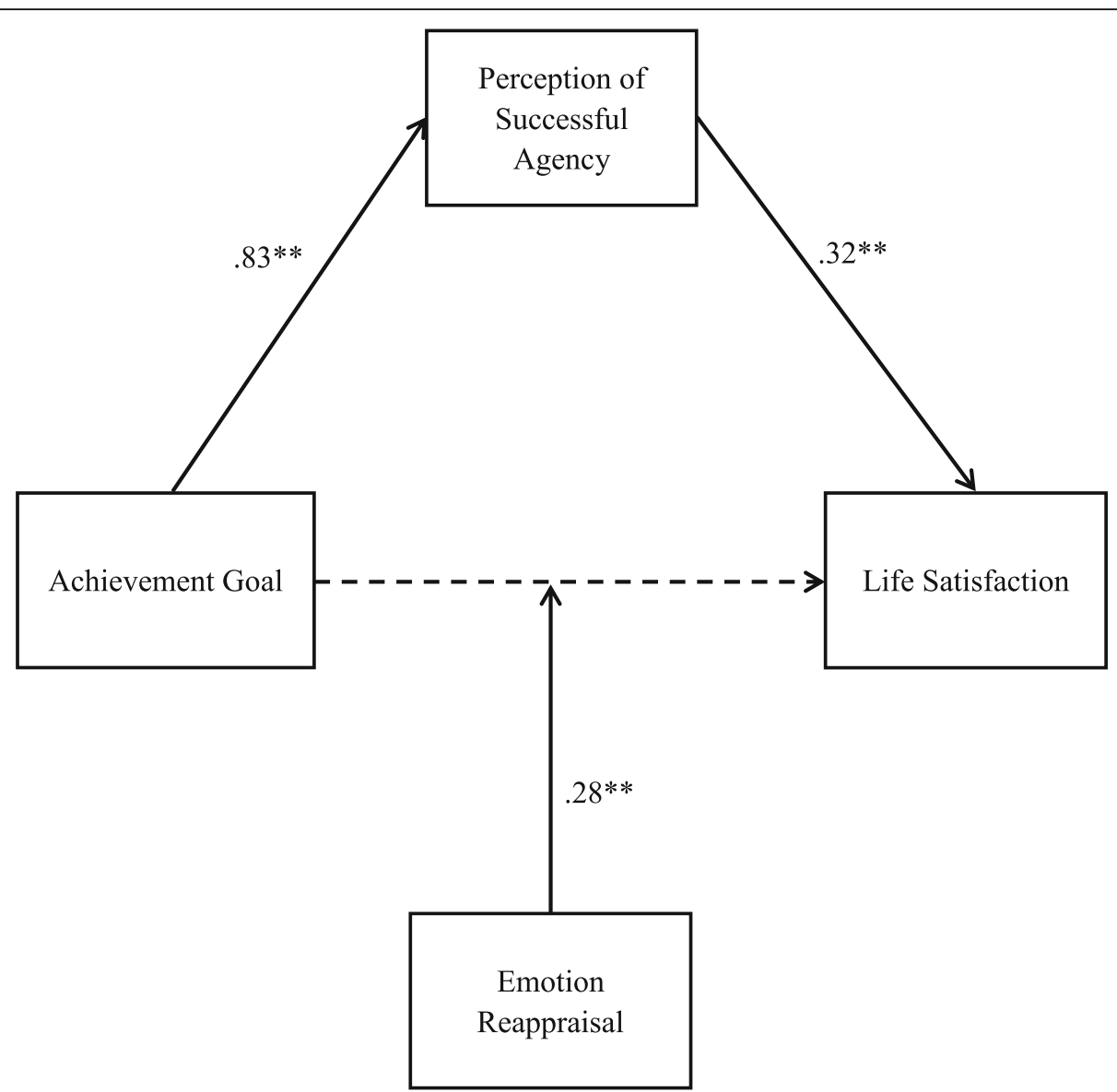

Fig. 2 Conceptual and statistical diagram. Research model with important coefficients. Effect size $R^{2}=.34,90 \% \mathrm{Cl}[.24,40]$

better at work, which is actually beneficial to career development in the long run. Consequently, he may feel more positive instead of frustrated or hopeless. This reappraisal would re-motivate him to continue working hard and improving himself until he succeeds.

This research has several limitations that could be solved in future research. First, caution should be exercised before generalizing our results based on Chinese data to Western societies. The meanings of some constructs may be different in China than in Western societies. Although there is no evidence showing the constructs used in the present study contain inconsistent meanings across different cultures, the previous literature indicates that some well-established concepts in Western culture are perceived in another way in China (e.g., Cheung et al., 2001; Wang, 2007). Future studies can directly test whether this difference applies to the study variables in this research. Second, the study is based on cross-sectional data. Therefore, our findings may not imply causality. In future studies, causal inference may be drawn based on experimental data. Meanwhile, caution should be taken for using crosssectional data to test mediation (Kline, 2015; Maxwell, Cole, \& Mitchell, 2011) because cross-sectional analysis can imply the existence of an indirect effect even when the true longitudinal indirect effect is zero. Adopting a longitudinal design in future research would help provide stronger evidence for the process account. Third, the sample size is limited in the present study. Future research can avoid this problem by adopting the sample size estimation approach suggested by Moinester and Gottfried (2014), which should be done before or at an early stage of a study. Fourth, we only identify one moderator in our model. Scholars may investigate other ways through which the relationship between achievement goals and life satisfaction is moderated. For example, similar to emotion reappraisal, psychological resilience refers to the capacity of positive adaptation in adversity (Ong, Bergeman, Bisconti, \& Wallace, 2006). According to this definition, it is also a potential moderator between achievement goals and life satisfaction. Fifth, we do not explore the relationships between different types of achievement goals and life satisfaction. Previous research has shown that different types of achievement goals have competing effects on performance (Grant \& Dweck, 2003), selfregulation (Lee et al., 2003), and reactions to imperfection (Stoeber, Stoll, Pescheck, \& Otto, 2008); therefore, it is 
essential to further test whether each type of achievement goal has similar or distinct effects on life satisfaction in future studies. Finally, we did not collect participants' information regarding whether they work in urban or rural environments, which has been shown to be related to well-being (Liang \& Wang, 2014). Future research should control for this variable.

\section{Conclusions}

Through a survey study of 225 participants in China, we find that achievement goals are positively related to life satisfaction. Furthermore, the relationship between achievement goals and life satisfaction is mediated by perception of successful agency and moderated by emotion reappraisal. This research provides a comprehensive understanding of how, why, and when achievement goals boost life satisfaction, which is theoretically contributive and practically important.

\section{Abbreviations}

CFI: Comparative fit index; Cl: Confidence interval; IPIP: International Personality Item Pool; NNFI: Non-normed fit index; RMSEA: Root mean square error of approximation; SE: Standard error

\section{Acknowledgements}

None

\section{Availability of data and materials}

All datasets and materials that were used in this research are available at https://pan.baidu.com/s/1qXLFvq8.

\section{Authors' contributions}

WW and $J$ conceived and designed the study. GS, ZC, and XZ conducted the survey. WW, JL, and GS wrote the paper. ZC and XZ reviewed and edited the manuscript. All authors read and approved the manuscript.

\section{Funding}

The authors acknowledge the financial support of the National Natural Science Foundation of China (grant no. 71472123) and the Young College Teachers' Training Scheme of Shanghai (grant no. ZZSD15094) in the data collection process.

\section{Ethics approval and consent to participate}

All procedures performed in studies involving human participants were in accordance with the ethical standards of the institutional and national research committee and with the 1964 Helsinki declaration and its later amendments or comparable ethical standards.

\section{Consent for publication}

Not applicable

\section{Competing interests}

The authors declare that they have no competing interests.

\section{Publisher's Note}

Springer Nature remains neutral with regard to jurisdictional claims in published maps and institutional affiliations.

\section{Author details}

'Shanghai Jiao Tong University, 1954 Huashan Road, Shanghai, China 2Shanghai University, 99 Shangda Road, Shanghai, China. ${ }^{3}$ Central University of Finance and Economics, 39 South College Road, Beijing, China.

${ }^{4}$ Macquarie University, Balaclava Road, Sydney, Australia.
Received: 27 July 2017 Accepted: 26 October 2017

Published online: 22 December 2017

\section{References}

Ablard, K. E., \& Lipschultz, R. E. (1998). Self-regulated learning in high-achieving students: relations to advanced reasoning, achievement goals, and gender. Journal of Educational Psychology, 90, 94-101 doi:10.1037/0022-0663.90.1.94

Adams, G. A., King, L. A., \& King, D. W. (1996). Relationships of job and family involvement, family social support, and work-family conflict with job and life satisfaction. Journal of Applied Psychology, 81, 411-420 doi:10.1037/0021-9010. 81.4 .411$.

Aiken, L. S., \& West, S. G. (1991). Multiple regression: testing and interpreting interactions. Thousand Oaks: Sage.

Anderman, L. H., \& Anderman, E. M. (1999). Social predictors of changes in students' achievement goal orientations. Contemporary Educational Psychology, 24, 21-37 doi:10.1006/ceps.1998.0978.

Aronson, E., \& Mills, J. (1959). The effects of severity of initiation on liking for a group. Journal of Abnormal and Social Psychology, 59, 177-181 doi:10.1037/ h0047195.

Bachman, J. G., \& O'Malley, P. M. (1977). Self-esteem in young men: a longitudinal analysis of the impact of educational and occupational attainment. Journal of Personality and Social Psychology, 35, 365-380 doi:10.1037/0022-3514.35.6.365.

Bailey, T. C., Eng, W., Frisch, M. B., \& Snyder, C. R. (2007). Hope and optimism as related to life satisfaction. The Journal of Positive Psychology, 2, 168-175 doi:10.1080/17439760701409546.

Baron, R. M., \& Kenny, D. A. (1986). The moderator-mediator variable distinction in social psychological research: conceptual, strategic, and statistical consideration. Journal of Personality and Social Psychology, 51, 1173-1182 doi:10.1037/0022-3514.51.6.1173.

Bentler, P. M. (1990). Comparative fit indexes in structural models. Psychological Bulletin, 107, 238-246 doi:10.1037/0033-2909.107.2.238.

Bong, M. (2009). Age-related differences in achievement goal differentiation. Journal of Educational Psychology, 101, 879-896 doi:10.1037/a0015945.

Brislin, R. W. (1986). The wording and translation of research instruments. In W. Lonner, \& J. Berry (Eds.), Field methods in cross-cultural research, (pp. 137-164). Beverly Hills: Sage.

Bronk, K. C., Hill, P. L., Lapsley, D. K., Talib, T. L., \& Finch, H. (2009). Purpose, hope, and life satisfaction in three age groups. The Journal of Positive Psychology, 4, 500-510 doi:10.1080/17439760903271439.

Brown, J. D., \& Dutton, K. A. (1995). The thrill of victory, the complexity of defeat: Self-esteem and people's emotional reactions to success and failure. Journal of Personality and Social Psychology, 68, 712-722 doi:10.1037/0022-3514.68.4.712.

Canha, L., Simões, C., Matos, M. G., \& Owens, L. (2016). Well-being and health in adolescents with disabilities. Psicologia: Reflexão e Crítica, 29(1), 32-39 doi:10. 1186/s41155-016-0041-9.

Capa, R. L., Audiffren, M., \& Ragot, S. (2008). The interactive effect of achievement motivation and task difficulty on mental effort. International Journal of Psychophysiology, 70, 144-150 doi:10.1016/j.jpsycho.2008.06.007.

Chang, E. C. (2003). A critical appraisal and extension of hope theory in middleaged men and women: is it important to distinguish agency and pathways components? Journal of Social and Clinical Psychology, 22, 121-143 doi:10.1521/jscp.22.2.121.22876.

Chen, R., Austin, J. P., Miller, J. K., \& Piercy, F. P. (2015). Chinese and American individuals' mate selection criteria: updates, modifications, and extensions. Journal of Cross-Cultural Psychology, 46, 101-118 doi:10.1177/0022022114551793.

Cheng, Z., \& Smyth, R. (2015). Sex and happiness. Journal of Economic Behavior and Organization, 112, 26-32 doi:10.1016/j.jebo.2014.12.030.

Cheng, Z., \& Smyth, R. (in press). China's imbalanced sex ratio and satisfaction with marital relations. Singapore Economic Review.

Cheng, Z., Wang, H., \& Smyth, R. (2014). Happiness and job satisfaction in urban China: a comparative study of two generations of migrants and urban locals. Urban Studies, 51, 2160-2184 doi:10.1177/0042098013506042.

Cheung, F. M., Leung, K., Zhang, J. X., Sun, H. F., Gan, Y. Q., Song, W. Z., \& Xie, D. (2001). Indigenous Chinese personality constructs: is the five-factor model complete? Journal of Cross-Cultural Psychology, 32, 407-433 doi:10.1177/ 0022022101032004003

Cohen, J. (1990). Things I have learned (so far). American Psychologist, 45, 1304-1312 doi:10.1037/0003-066x.45.12.1304

Cohen, J Cohen, P. West, S. G, \& Aiken, L S. (2003). Applied multiple regression correlation analysis for the behavioral sciences, (3rd ed., ). Hillsdale: Erlbaum. 
Crutzen, R., \& Peters, G. J. Y. (2017). Scale quality: alpha is an inadequate estimate and factor-analytic evidence is needed first of all. Health Psychology Review, 11, 242-247 doi:10.1080/17437199.2015.1124240.

Cury, F., Elliot, A., Sarrazin, P., Da Fonseca, D., \& Rufo, M. (2002). The trichotomous achievement goal model and intrinsic motivation: a sequential mediational analysis. Journal of Experimental Social Psychology, 38, 473-481 doi:10.1016/ s0022-1031(02)00017-3.

Diener, E., Diener, M., \& Diener, C. (1995). Factors predicting the subjective wellbeing of nations. Journal of Personality and Social Psychology, 69, 851-864 doi:10.1037/0022-3514.69.5.851.

Diener, E. D., Emmons, R. A., Larsen, R. J., \& Griffin, S. (1985). The satisfaction with life scale. Journal of Personality Assessment, 49, 71-75 doi:10.1207/ s15327752.jpa4901_13.

Diener, E. D., Oishi, S., \& Lucas, R. E. (2003). Personality, culture, and subjective well-being: emotional and cognitive evaluations of life. Annual Review of Psychology, 54, 403-425 doi:10.1146/annurev.psych.54.101601.145056.

Du, H., Bernardo, A. B., \& Yeung, S. S. (2015). Locus-of-hope and life satisfaction: the mediating roles of personal self-esteem and relational self-esteem. Personality and Individual Differences, 83, 228-233 doi:10.1016/j.paid.2015.04.026.

Efraty, D., Sirgy, M. J., \& Claiborne, C. B. (1991). The effects of personal alienation on organizational identification: a quality-of-work-life model. Journal of Business and Psychology, 6, 57-78 doi:10.1007/bf01013685.

Ellenhorn, R. (2005). Parasuicidality and patient careerism: treatment recidivism and the dialectics of failure. American Journal of Orthopsychiatry, 75, 288-303 doi:10.1037/0002-9432.75.2.288.

Esterman, M., Reagan, A., Liu, G., Turner, C., \& DeGutis, J. (2014). Reward reveals dissociable aspects of sustained attention. Journal of Experimental Psychology: General, 143, 2287-2295 doi:10.1037/xge0000019.

Feinberg, M., Willer, R., Antonenko, O., \& John, O. P. (2012). Liberating reason from the passions overriding intuitionist moral judgments through emotion reappraisal. Psychological Science, 23, 788-795 doi:10.1177/0956797611434747.

Feldman, D. B., \& Snyder, C. R. (2005). Hope and the meaningful life: theoretical and empirical associations between goal-directed thinking and life meaning. Journal of Social and Clinical Psychology, 24, 401-421 doi:10.1521/jscp.24.3.401.65616.

Flanagan, M. J., Putwain, D. W., \& Caltabiano, M. L. (2015). The relationship between goal setting and students' experience of academic test anxiety. International Journal of School \& Educational Psychology, 3, 189-201 doi:10. 1080/21683603.2015.1060910

Gallagher, M. W., \& Lopez, S. J. (2009). Positive expectancies and mental health: identifying the unique contributions of hope and optimism. The Journal of Positive Psychology, 4, 548-556 doi:10.1080/17439760903157166.

Gannon, N., \& Ranzijn, R. (2005). Does emotional intelligence predict unique variance in life satisfaction beyond IQ and personality? Personality and Individual Differences, 38, 1353-1364 doi:10.1016/j.paid.2004.09.001.

Gao, W., \& Smyth, R. (2010). What keeps China's migrant workers going? Expectations and happiness among China's floating population. Journal of the Asia Pacific Economy, 16, 163-182 doi:10.1080/13547860.2011.564749.

Goldberg, L. R. (1999). A broad-bandwidth, public-domain, personality inventory measuring the lower-level facets of several five-factor models. In I. Mervielde, I. J. Deary, F. De Fruyt, \& F. Ostendorf (Eds.), Personality psychology in Europe, (vol. 7, pp. 7-28). Tilburg, The Netherlands: Tilburg University Press.

Gould, S. (1980). Need for achievement, career mobility, and the MexicanAmerican college graduate. Journal of Vocational Behavior, 16, 73-82 doi:10. 1016/0001-8791(80)90039-1.

Grant, H., \& Dweck, C. S. (2003). Clarifying achievement goals and their impact. Journa of Personality and Social Psychology, 85, 541-553 doi:10.1037/0022-3514.85.3.541.

Greenhaus, J. H., Bedeian, A. G., \& Mossholder, K. W. (1987). Work experiences, job performance, and feelings of personal and family wellbeing. Journal of Vocational Behavior, 31, 200-215 doi:10.1016/00018791(87)90057-1.

Gross, J. J. (1998). Antecedent-and response-focused emotion regulation: divergent consequences for experience, expression, and physiology. Journal of Personality and Social Psychology, 74, 224-237 doi:10.1037/0022-3514.74.1.224.

Gross, J. J. (2002). Emotion regulation: affective, cognitive, and social consequences. Psychophysiology, 39, 281-291 doi:10.1017/ s0048577201393198.

Gross, J. J., \& John, O. P. (2003). Individual differences in two emotion regulation processes: implications for affect, relationships, and well-being. Journal of Personality and Social Psychology, 85, 348-362 doi:10.1037/0022-3514.85.2.348.

Harackiewicz, J. M., Barron, K. E., Tauer, J. M., Carter, S. M., \& Elliot, A. J. (2000). Short-term and long-term consequences of achievement goals: predicting interest and performance over time. Journal of Educational Psychology, 92, 316-330 doi:10.1037/0022-0663.92.2.316.

Harackiewicz, J. M., Barron, K. E., Tauer, J. M., \& Elliot, A. J. (2002). Predicting success in college: a longitudinal study of achievement goals and ability measures as predictors of interest and performance from freshman year through graduation. Journal of Educational Psychology, 94, 562-575 doi:10. 1037/0022-0663.94.3.562.

Harackiewicz, J. M., \& Sansone, C. (1991). Goals and intrinsic motivation: you can get there from here. Advances in Motivation and Achievement, 7, 21-49.

Hayes, A. F. (2013). Introduction to mediation, moderation, and conditional process analysis: a regression-based approach. New York: Guilford Press.

Hewitt, P. L., \& Flett, G. L. (1991). Dimensions of perfectionism in unipolar depression. Journal of Abnormal Psychology, 100, 98-101 doi:10.1037/0021-843x.100.1.98.

Hirschfeld, R. R., Lawson, L., \& Mossholder, K. W. (2004). Moderators of the relationship between cognitive ability and performance: general versus context-specific achievement motivation. Journal of Applied Social Psychology, 34, 2389-2409 doi:10.1111/j.1559-1816.2004.tb01983.x.

Hulleman, C. S., Schrager, S. M., Bodmann, S. M., \& Harackiewicz, J. M. (2010). A meta-analytic review of achievement goal measures: different labels for the same constructs or different constructs with similar labels? Psychological Bulletin, 136, 422-449 doi:10.1037/a0018947.

Johnson, W., \& Krueger, R. F. (2006). How money buys happiness: genetic and environmental processes linking finances and life satisfaction. Journal of Personality and Social Psychology, 90, 680-691 doi:10.1037/0022-3514.90.4.680.

Joseph, R. P., Royse, K. E., Benitez, T. J., \& Pekmezi, D. W. (2014). Physical activity and quality of life among university students: exploring selfefficacy, self-esteem, and affect as potential mediators. Quality of Life Research, 23, 659-667 doi:10.1007/s11136-013-0492-8.

Keller, C., \& Siegrist, M. (2010). Psychological resources and attitudes toward people with physical disabilities. Journal of Applied Social Psychology, 40, 389-401 doi:10.1111/j.1559-1816.2009.00579.x.

Kline, R. B. (2015). The mediation myth. Basic and Applied Social Psychology, 37, 202-213 doi:10.1080/01973533.2015.1049349.

Leary, M. R., Tambor, E. S., Terdal, S. K., \& Downs, D. L. (1995). Self-esteem as an interpersonal monitor: the sociometer hypothesis. Journal of Personality and Social Psychology, 68, 518-530 doi:10.1037/0022-3514.68.3.518.

Lee, F. K., Sheldon, K. M., \& Turban, D. B. (2003). Personality and the goalstriving process: the influence of achievement goal patterns, goal level, and mental focus on performance and enjoyment. Journal of Applied Psychology, 88, 256-265 doi:10.1037/0021-9010.88.2.256.

Li, J., Chen, Y., \& Huang, X. (2015). Materialism moderates the effect of accounting for time on prosocial behaviors. The Journal of Social Psychology, 155, 576-589 doi:10.1080/00224545.2015.1024192.

Liang, Y., \& Wang, P. (2014). Influence of prudential value on the subjective well-being of Chinese urban-rural residents. Social Indicators Research, 118, 1249-1267 doi:10.1007/s11205-013-0471-z.

Little, T. D., Cunningham, W. A., Shahar, G., \& Widaman, K. F. (2002). To parcel or not to parcel: exploring the question, weighing the merits. Structural Equation Modeling, 9, 151-173 doi:10.1207/s15328007sem0902_1.

Mackinnon, D. P., Lockwood, C. M., Hoffman, J. M., West, S. G., \& Sheets, V. (2002). A comparison of methods to test mediation and other intervening variable effects. Psychological Methods, 7, 83-104 doi:10.1037/ 1082-989x.7.1.83.

Magaletta, P. R., \& Oliver, J. M. (1999). The hope construct, will, and ways: their relations with self-efficacy, optimism, and general well-being. Journal of Clinical Psychology, 55, 539-551 doi:10.1002/(sici)1097-467. 9(199905)55: \%3C539::aid-jclp2\%3E3.0.co;2-g.

Matud, M. P., Bethencourt, J. M., \& Ibáñez, I. (2014). Relevance of gender roles in life satisfaction in adult people. Personality and Individual Differences, 70, 206-211 doi:10.1016/j.paid.2014.06.046.

Maxwell, S. E., Cole, D. A., \& Mitchell, M. A. (2011). Bias in cross-sectional analyses of longitudinal mediation: partial and complete mediation under an autoregressive model. Multivariate Behavioral Research, 46, 816-841 doi:10. 1080/00273171.2011.606716.

McNeish, D. (in press). Thanks coefficient alpha, we'll take it from here. Psychological Methods. doi:10.1037/met0000144.

Moinester, M., \& Gottfried, R. (2014). Sample size estimation for correlations with pre-specified confidence interval. The Quantitative Methods for Psychology, 10, 124-130 doi:10.20982/tqmp.10.2.p0124.

Nunes, R. P., Melo, R. L. P. D., Júnior, S., \& Eulálio, M. D. C. (2016). Relationship between coping and subjective well-being of elderly from the interior of the 
Brazilian Northeast. Psicologia: Reflexão e Crítica, 29, 33-40 doi:10.1186/ s41155-016-0032-x

O'Sullivan, G. (2011). The relationship between hope, eustress, self-efficacy, and life satisfaction among undergraduates. Social Indicators Research, 101, 155-172 doi:10.1007/s11205-010-9662-z.

Ojeda, L., Flores, L. Y., \& Navarro, R. L. (2011). Social cognitive predictors of Mexican American college students' academic and life satisfaction. Journal of Counseling Psychology, 58, 61-71 doi:10.1037/a0021687.

Ong, A. D., Bergeman, C. S., Bisconti, T. L., \& Wallace, K. A. (2006). Psychological resilience, positive emotions, and successful adaptation to stress in later life. Journal of Personality and Social Psychology, 91, 730-749 doi:10.1037/00223514.91.4.730.

Park, J., \& Baumeister, R. F. (2017). Meaning in life and adjustment to daily stressors. The Journal of Positive Psychology, 12, 333-341 doi:10.1080/ 17439760.2016.1209542

Park, N., Park, M., \& Peterson, C. (2010). When is the search for meaning related to life satisfaction? Applied Psychology: Health and Well-Being, 2, 1-13 doi:10. 1111/j.1758-0854.2009.01024.x.

Peters, G. J., Abraham, C., \& Crutzen, R. (2015). Full disclosure: doing behavioural science necessitates sharing. European Health Psychologist, 14, 77-84 doi:10. 1037/e544792013-002.

Phillips, J. M., \& Gully, S. M. (1997). Role of goal orientation, ability, need for achievement, and locus of control in the self-efficacy and goal-setting process. Journal of Applied Psychology, 82, 792-802 doi:10.1037/0021-9010.82.5.792.

Pintrich, P. R. (2000). An achievement goal theory perspective on issues in motivation terminology, theory, and research. Contemporary Educational Psychology, 25, 92-104 doi:10.1006/ceps.1999.1017.

Preacher, K. J., \& Hayes, A. F. (2008). Asymptotic and resampling strategies for assessing and comparing indirect effects in multiple mediator models. Behavioral Research Methods, 40, 879-891 doi:10.3758/brm.40.3.879.

Przepiorka, A. M. (2017). Psychological determinants of entrepreneurial success and life-satisfaction. Current Psychology, 36, 304-315 doi:10.1007/s12144-016-9419-1.

Reynolds, W. M. (1982). Development of reliable and valid short forms of the Marlowe-Crowne Social Desirability Scale. Journal of Clinical Psychology, 38, 119-125 doi:10.1002/1097-4679(198201)38:1\%3C119::aid-jclp. 2270380118\%3E3.0.co; $2-\mathrm{i}$.

Rosenthal, R. (1991). Meta-analytic procedures for social research. Newbury Park: Sage. Ryan, R. M., \& Deci, E. L. (2000). Self-determination theory and the facilitation of intrinsic motivation, social development, and well-being. American Psychologist, 55, 68-78 doi:10.1037/0003-066x.55.1.68.

Saleem, M., Anderson, C. A., \& Barlett, C. P. (2015). Assessing helping and hurting behaviors through the Tangram help/hurt task. Personality and Social Psychology Bulletin, 41, 1345-1362 doi:10.1177/0146167215594348.

Senko, C., \& Harackiewicz, J. M. (2005). Achievement goals, task performance, and interest: why perceived goal difficulty matters. Personality and Social Psychology Bulletin, 31, 1739-1753 doi:10.1177/0146167205281128.

Singley, D. B., Lent, R. W., \& Sheu, H. B. (2010). Longitudinal test of a social cognitive model of academic and life satisfaction. Journal of Career Assessment, 18, 133-146 doi:10.1177/1069072709354199.

Smithson, M. (2001). Correct confidence intervals for various regression effect sizes and parameters: the importance of noncentral distributions in computing intervals. Educational and Psychological Measurement, 61, 605-632 doi:10.1177/00131640121971392

Snyder, C. R., Harris, C., Anderson, J. R., Holleran, S. A., Irving, L. M., Sigmon, S. T., Yoshinobu, L., Gibb, J., Langelle, C., \& Harney, P. (1991). The will and the ways: development and validation of an individual-differences measure of hope. Journal of Personality and Social Psychology, 60, 570-585 doi:10.1037/00223514.60.4.570.

Spencer-Rodgers, J., Peng, K., Wang, L., \& Hou, Y. (2004). Dialectical self-esteem and east-west differences in psychological well-being. Personality and Social Psychology Bulletin, 30, 1416-1432 https://doi.org/10.1177/0146167204264243.

Steger, M. F., Frazier, P., Oishi, S., \& Kaler, M. (2006). The meaning in life questionnaire: assessing the presence of and search for meaning in life. Journal of Counseling Psychology, 53, 80-93 doi:10.1037/0022-0167.53.1.80

Steiger, J. H. (1990). Structural model evaluation and modification: an interval estimation approach. Multivariate Behavioral Research, 25, 173-180 doi:10. 1207/s15327906mbr2502_4.

Stoeber, J., Stoll, O., Pescheck, E., \& Otto, K. (2008). Perfectionism and achievement goals in athletes: relations with approach and avoidance orientations in mastery and performance goals. Psychology of Sport and Exercise, 9, 102-121 doi:10.1016/j.psychsport.2007.02.002.
Stroessner, S. J., Scholer, A. A., Marx, D. M., \& Weisz, B. M. (2015). When threat matters: self-regulation, threat salience, and stereotyping. Journal of Experimental Social Psychology, 59, 77-89 doi:10.1016/j.jesp.2015.03.003.

Tay, C., Ang, S., \& Van Dyne, L. (2006). Personality, biographical characteristics, and job interview success: a longitudinal study of the mediating effects of interviewing self-efficacy and the moderating effects of internal locus of causality. Journal of Applied Psychology, 91, 446-454 doi:10.1037/0021-9010.91.2.446.

Wang, C. L. (2007). Guanxi vs. relationship marketing: exploring underlying differences. Industrial Marketing Management, 36, 81-86 doi:10.1016/j. indmarman.2005.08.002f.

Weinstein, N., \& Ryan, R. M. (2010). When helping helps: autonomous motivation for prosocial behavior and its influence on well-being for the helper and recipient. Journal of Personality and Social Psychology, 98, 222-244.

\section{Submit your manuscript to a SpringerOpen ${ }^{\circ}$ journal and benefit from:}

- Convenient online submission

- Rigorous peer review

- Open access: articles freely available online

- High visibility within the field

- Retaining the copyright to your article

Submit your next manuscript at $>$ springeropen.com 